\title{
The use of simple compartmental models in sheep metabolism studies
}

\author{
By J. A. Milne and R. W. Mayes, Hill Farming Research Organisation, Bush \\ Estate, Penicuik, Midlothian EH26 oPY
}

In ruminant animals there is still a lack of precision in the prediction of the output of animal products, such as milk, meat and wool, from a given input of feed. One of the main reasons is the complex nature of the digestion process with the end-products of rumen fermentation providing the principal source of energy to the tissues and microbial protein being an important source of absorbed amino acids. Furthermore, in most production systems the ruminant will at some stage be in negative nutrient balance and have to use body tissue, for example, for milk production or fetal growth, or require to adjust its metabolism in response to climate. Thus the need to know the quantities of nutrients absorbed and how they, and those from the tissues, are metabolized and converted into animal product has been the stimulus for quantitative research using isotopic tracers in the study of the transfer of substrates within the body of the ruminant.

Quantitative measurements require the use of a model to provide a simplified description of the physiological processes and a means whereby an analysis of these processes can be made. Such models have three elements: ( $\mathrm{I}$ ) compartments, which represent a particular metabolite and situation, (2) interrelationships, which represent transfers or metabolic transformations, and (3) rates of transfer, which must be able to be expressed in mathematical terms (see Waterlow et al. 1978).

This approach was originally applied to ruminants in the study of metabolites in a single compartment when animals were in a steady-state and given either a single injection or a continuous infusion of isotopic tracer. Among the metabolites studied were glucose, free fatty acids and urea (see Leng, 1970). However, single compartment models have the disadvantage that in most ruminant systems they do not adequately represent reality.

An awareness of this led to models with larger numbers of compartments. These models can be solved by compartmental analysis using the time-curve of specific activity or enrichment (SA) from samples taken from a single compartment. However, the computation becomes more complex with an increase in compartment number (see Shipley \& Clark, 1972). Difficulties can arise in the fitting of a sum of exponentials leading to serious errors in the estimation of parameters, particularly with ill-conditioned data. An extension of this approach has been to use a generalized mathematical compartment model such as the SAAM computer program developed by Berman \& Weiss (1967) and exploited subsequently by others (for example, Weber et al. 1980). It has uses in model-building and in highlighting where unsuspected physiological processes may lie, but great care is required in interpretation if misleading conclusions are not to be drawn. 
Measurements of rates of input and output or interchange between compartments are possible without recourse to multi-exponential curve-fitting techniques. However, all the compartments require to be sampled. Compartment sizes are not estimated and the transfer rates obtained are dependent on estimations of irreversible loss rate (ILR) from each compartment. Initially the approach was restricted to models in which non-reversible transfers were assumed. Examples can be found in the experiments of Annison et al. (1963) in the measurement of glucose and lactate transfers, in the three-compartment model used by Bergman et al. (1968) to determine rates of glycerol conversion to glucose and carbon dioxide, and in the study of transfers between plasma urea and rumen $\mathrm{CO}_{2}$ by MacRae et al. (1979). Where transfers between compartments are considered to operate in both directions, the general method of solution was given by Mann \& Gurpide (1966) and its first application to glucose metabolism in rats was described by Depocas \& de Freitas (1970).

The first use of such interchanging models in ruminant nutrition was by Nolan et al. (1976) for the estimation of nitrogen transfers between rumen ammonia, plasma urea and caecal $\mathrm{NH}_{3}$ compartments. A number of further applications of the general method have been reported recently, dealing with such issues as interconversions of volatile fatty acids (VFA) in the rumen (Mayes et al. I98I; Rowe et al. 1981; Sharp et al. 1982), the synthesis, interaction and oxidation of circulating ketone bodies (Pethick \& Lindsay, 1982) and the synthesis of glucose from propionate and amino acids (Egan et al. 1983; Wilson et al. 1983). It is the application of the general model given by Mann \& Gurpide (1966) to ruminant studies that will be considered in the present paper, although some of the points discussed have a wider implication to other approaches to compartment modelling.

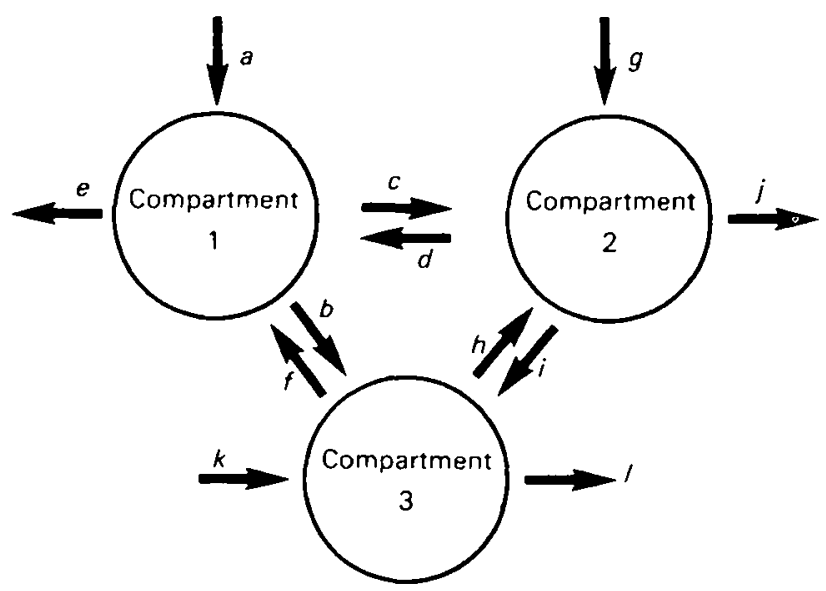

Fig. 1. Diagrammatic representation of a general open, fully interchanging three-compartment model; $a \ldots$ are the rates of flow of material. 


\section{Description of approach}

To obtain a unique solution to a general open $n$-compartment model, where all possible pathways are considered, one compartment is given a constant infusion or single dose of isotopic tracer under steady-state conditions and each compartment is sampled to determine its SA. Tracer is administered to each compartment in turn under, ideally, identical conditions. A series of $\left(n^{2}+n\right)$ simultaneous equations is then set up and solved to estimate the rates of flow through $n$ compartments. Fig. I shows a three-compartment model with the directions of the rates of flow indicated. Since the system is in steady-state, the rates of inflow and outflow of unlabelled material (tracee) through each compartment are identical. The movement through compartment $I$ in Fig. $I$ is described by the equation:

$$
a+d+f-b-c-e=0
$$

where $a \ldots f$ are rates of flow of tracee. Also, the total flows of tracer in and out of each compartment must be equal and thus a further series of equations can be derived describing tracer flows. If the infusion of tracer is into compartment $\mathrm{I}$ then the equations for compartments $I, 2$ and 3 are respectively:

$$
\begin{gathered}
-\mathrm{SA}_{11}(b+c+e)+\mathrm{SA}_{12} d+\mathrm{SA}_{13} f=-I_{1} \\
-\mathrm{SA}_{12}(d+h+j)+\mathrm{SA}_{11} c+\mathrm{SA}_{13} i=0 \\
\text { and } \\
-\mathrm{SA}_{13}(f+i+l)+\mathrm{SA}_{11} b+\mathrm{SA}_{12} h=0
\end{gathered}
$$

where $\mathrm{SA} x$ is the SA of compartment $y$ when compartment $x$ is being infused and $I_{x}$ is the infusion rate of tracer into compartment $x$. Similar sets of equations can be obtained when tracers are infused into compartments 2 and 3 . A unique solution to the set of twelve equations derived can be obtained.

\section{Technical issues}

Because of the large number of samples involved with the single-injection approach, the continuous-infusion method has been more widely used and will be the method discussed in the remainder of the present paper.

Within-and between-animal variation. The measurement of SA is usually made on a series of samples taken from each compartment over a period of $\mathrm{I}-8 \mathrm{~h}$ after it is considered that a plateau SA has been reached. Variation in SA values for each animal (the within-animal error) contributes to the between-animal error term for the transfer rates used to estimate the precision of the experiment. Smith $e t$ al. (1984) have described a method for estimating the within-animal standard errors of transfer rates. From separate models in sheep involving rumen VFA, plasma urea and plasma glucose, they have shown that between six and twelve samples are 
necessary per infusion to ensure that the within-animal variance is small in relation to the between-animal variance, when six sheep per treatment are used. A reduction in the number of animals used in an experiment implies a need to take a greater number of samples for the measurement of SA. Also, an inspection of the within-sheep standard errors can give some indication of the adequacy of the data from an animal in fitting the model.

Between-infusion variation. One of the assumptions of the approach is that similar steady-state conditions apply throughout all infusions. This can obviously be a problem if feed intake or feeding patterns vary. However, even without such variations, Wilson (1982) observed that when $\left[{ }^{3} \mathrm{H}\right]$ glucose was infused on separate occasions the coefficients of variation between infusion days for $\left[{ }^{3} \mathrm{H}\right]$ glucose SA were as high as $15 \%$, although they averaged $6-8 \%$. In a changing situation such as in pregnancy or lactation the problem may be exacerbated. One means of overcoming this difficulty would be to infuse simultaneously different isotope tracers into separate compartments.

The need to complete a set of infusions within the shortest possible period has to be set against other factors. For reliable estimates of SA, sufficient time must be allowed for secondary pools to achieve plateau values. If this is in doubt, it is possible to obtain secondary and primary compartment mean SA from the areas under their SA $v$. time curves obtained by sampling throughout and after the termination of the infusion (Pethick et al. I98r).

Attempting to reduce the time between infusions increases the likelihood of residual labelling in the sampled compartments before subsequent infusions begin. Whereas residual labelling from the sampled compartments can be ignored, since new equilibria will be reached in each subsequent infusion, residual label entering from outside the model system could create problems. However, if residual labelling remains constant before a subsequent infusion, the residual labelling can be subtracted to obtain plateau SA attributable to the new infusion. As most model systems would probably contain residual label from both sources, it is difficult to define a suitable correction procedure. Obviously, greater accuracy will be obtained if subsequent plateau labelling is high relative to the residual levels.

Mixing within compartments and their sampling. When the infused compartment is within the blood or plasma, the site of sampling is usually remote from the infusion site such that adequate mixing can be assumed to have occurred. However, as the plasma compartment is not homogeneous because of differences in the sites of influx and efflux of material within the circulatory system, choice of infusion and sampling sites is of considerable importance depending on the metabolite being studied.

In contrast to the relatively-small and rapidly-turning-over plasma compartments in which mixing is considered adequate, compartments within the rumen are generally much larger and have longer turnover times. The heterogeneous nature of rumen contents and the stratification of solid, liquid and gaseous phases can lead to an inadequate distribution of tracer and to variations in concentration of tracee. Proximity of infusion and sampling sites can also 
contribute to difficulties in obtaining samples which are representative of the rumen contents as a whole (Sutton et al. 1972), Several attempts have been made to overcome these difficulties.

Within-animal variability in rumen VFA SA values has been reduced on some occasions by the incorporation of tracer into the feed given to sheep fed continuously (Mayes et al. 1983). This was considered to be due to improved distribution of tracer throughout the rumen. Low within-sheep variabilities have often been achieved by the use of indwelling fabric-covered sampling frames (described by Wilson, 1982). However, the withdrawal of samples through these devices causes solid feed particles to aggregate around the sampler. Thus whilst the VFA SA of samples withdrawn through the sampler may be reasonably representative of the fluid close to the sampler, it is uncertain how representative such samples are of rumen contents as a whole.

Murray et al. (1976) have obtained reasonable estimates of rumen methane ILR by intraruminal infusion of an aqueous solution of radioactive methane and by sampling the gaseous phase. Reductions in within-sheep variability of $\mathrm{SA}$ of $\mathrm{CO}_{2}$ in the rumen were found when gas-phase $\mathrm{CO}_{2}$ was sampled compared with liquid-phase $\mathrm{CO}_{2}$ (R. W. Mayes and C. S. Lamb, unpublished results). However, for both methane and $\mathrm{CO}_{2}$ estimations, errors may arise due to insufficient equilibration throughout the liquid phase before passage of tracer to the gaseous phase.

\section{Interpretation of models}

Whilst all models are simplifications of reality, over-simplification can often lead to misinterpretation of results obtained. In order to select a model of the correct complexity for the intended purpose it is important to have as full a knowledge of the processes occurring between and outside the chosen compartments as possible. This can be illustrated by considering the difficulties that can often arise in interpretation when attempts are made to obtain values of net synthesis rates of metabolites, such as glucose, from precursors such as propionate or amino acids. The respective over- and underestimation of the contributions that acetate and propionate make to glucose synthesis due to 'crossover' of label in the TCA cycle is now well recognized (Krebs et al. 1966; Black, 1970). However, this problem is not unique to glucose synthesis. Similar effects can occur in a large number of situations where two-way interchange of tracer occurs. Examples of such effects are the apparent fixation of $\mathrm{CO}_{2}$ into glucose and overestimation of the oxidation rates of various amino acids and glucose (Lindsay \& Buttery, 1980).

The use of tracers labelled in specific positions can, on occasion, help to overcome some of these problems. They can, on the other hand, if used without careful consideration, lead to misinterpretation. Rowe et al. (1981) give an example of the misuse of $\left[\mathrm{I}-{ }^{14} \mathrm{C}\right]$ propionate to estimate rumen propionate ILR. The combined use of ${ }^{3} \mathrm{H}$ and ${ }^{14} \mathrm{C}$ compounds, similarly, requires caution since the metabolic fates of the labels may differ.

Transfer rates determined from isotope-dilution studies and net production 
rates obtained in other ways (e.g. expired $\mathrm{CO}_{2}$, output of nutrients in milk, etc.) may be combined within a single model. Care must be exercised in the interpretation of such models since the two approaches are not necessarily compatible. Respiratory $\mathrm{CO}_{2}$ output is lower than $\mathrm{CO}_{2}$ irreversible loss rate determined by tracers (Whitelaw, 1974) and, whilst corrections may be made to account for losses, for example, in faeces, urine and sweat, $\mathrm{CO}_{2}$ interchange reactions cannot be assessed if respiratory $\mathrm{CO}_{2}$ output is used.

Although some of the problems of interpretation described previously can be overcome using more complex models, it is virtually impossible to measure exactly, for example, the contribution of propionate to net glucose synthesis or the proportion of the plasma-free amino acid ILR which are truly oxidized by recourse to a modelling approach.

\section{Application to non-steady-state conditions}

The need to maintain steady-state conditions in order to construct valid models limits their usefulness. In most systems of animal production the ruminant cannot be regarded as being in steady-state throughout the periods of measurement; feeding patterns and aspects of diurnal variation are the major factors responsible. This applies to both housed and grazing ruminants. The use of steady-state assumptions under such conditions is theoretically invalid, whether the model is intended to reflect instantaneous transfer rates, or rates averaged over a period of time. Methods of quantifying transfers in models under non-steady-state conditions have been developed for plasma glucose in monogastric species (e.g. Radzuik et al. 1978) but as they are dependent on compartmental analysis they can be criticized for the same reasons as outlined earlier.

Changing the infusion rate of a tracer in synchrony with changes in flux-rate to maintain constant $\mathrm{SA}$ is, in theory, a simple means of determining a flux-rate under non-steady-state conditions (Gray et al. I g66). However, the technique is likely to be of little use generally since it is difficult to control tracer-infusion rate and is applicable only to single-compartment models. Morant et al. (1978) have described a method of estimating the instantaneous rumen production rate of a VFA using tracer infused at a constant rate. Knowledge of the size of the compartment and its rate of change in size is required; while this may be possible for compartments within the rumen, reliable estimations for compartments in the blood or plasma would be more difficult to obtain.

The method could be applicable to the formation of a series of multicompartment models whose parameters describe instantaneous transfer rates. The simultaneous equations used are the same as for steady-state models except that measured rates of change in both compartment size and in amounts of tracer in those compartments are included. Simultaneous infusions of different isotopic tracers into separate compartments would be necessary because of differences between infusion-days in the nature of the non-steady-state conditions. For non-steady-state rumen VFA models to be valid, mixing should be adequate. This can be assessed from changes in the concentrations of liquid-phase markers used to estimate rumen volume (see Morant et al. 1978). 
In most cases the desired model should describe average transfers for an extended period (usually $24 \mathrm{~h}$, to account for diurnal variations). It would thus be necessary to integrate the instantaneous transfer-rates (i.e. areas under transfer-rate $v$. time curves) over the period. Under non-steady-state conditions over a $24 \mathrm{~h}$ period, parameters derived from such models are likely to exhibit a cyclical pattern. In the summation of the instantaneous transfer-rates the over-all effects of the differential terms (e.g. SA. $Q \mathrm{~d}(\mathrm{I} / \mathrm{SA}) / \mathrm{d} t)$ will, to some extent, be reduced as their signs will change throughout the cycle. Where $Q$ is the compartment size, $I$ is the infusion rate of the tracer, $S A$ is the specific activity or excess isotopic abundance and $t$ is time, instantaneous ILR from a single pool $=$ $(I / \mathrm{SA}+\mathrm{SA} \cdot Q \mathrm{~d}(\mathrm{I} / \mathrm{SA}) / \mathrm{d} t)$ (Morant et al. 1978$)$. Identical estimates of $24 \mathrm{~h}$ VFA production rates have been found experimentally in sheep whether or not the differential term is included in the estimation (R. W. Mayes and J. A. Milne, unpublished results). If this finding is generally applicable the scope for development of models under non-steady-state conditions is considerably extended. The magnitude of error involved in assuming an instantaneous steady-state will depend on the size of the differential term relative to $I / \mathrm{SA}$. As the differential term is proportional to compartment size, the larger $I / \mathrm{SA}$ is relative to $Q$ the smaller will be the error involved if the differential term is ignored.

The error in omitting the differential is thus likely to decrease as the turnover times of the compartments decrease. It may therefore be possible to use this approach to models involving plasma compartments (having shorter turnover times than rumen VFA) with relatively little error.

\section{Future application}

The use of simple multi-compartment models of the type described has been limited compared with the numbers of experiments performed assuming single-compartment systems and has been confined largely to comparisons under steady-state conditions of transfer-rates in animals under widely-differing physiological states (for example, fed $v$. fasted and pregnant $v$. non-pregnant). However, the nutritional importance in ruminants of VFA and other metabolic intermediates, which can be quantified by modelling methods, enlarges the scope for the future of this technique in studies in which the effects of quantity or composition of diet are investigated. As treatment differences may be smaller, more replication will be necessary than in past studies. The use of more animals implies an increased analytical capability and greater quantities of tracer. However, new purification techniques which are rapid and give high yields of labelled metabolites should ease the analytical load and reduce the amount of isotope required per animal. For these models to be useful in quantifying nutrient and metabolite transfers in applied nutritional research, the results obtained must adequately represent the practical situation to which the research is being addressed. The application of the method to non-steady-state conditions described previously offers one means whereby these aims may be achieved. 


\section{REFERENCES}

Annison, E. F., Lindsay, D. B. \& White, R. R. (I963). Biochemical fournal 88, 243-248.

Bergman, E. W., Starr, D. J. \& Reulein, S. S. (1968). American Yournal of Physiology 215, $874-880$.

Berman, M. \& Weiss, M. F. (1967). SAAM 27 Manual. Bethesda: National Institutes of Health, USA.

Black, A. L. (1970). In Physiology of Digestion and Metabolism in the Ruminant, pp. 452-455 [A. T. Phillipson, editor]. Newcastle upon Tyne: Oriel Press.

Depocas, F. \& de Freitas, A. S. W. (1970). Canadian Journal of Physiology and Pharmacology $48,557-560$.

Egan, A. R., MacRae, J. C. \& Lamb, C. S. (1983). British Yournal of Nutrition 49, 373-384.

Gray, F. V., Weller, R. A., Pilgrim, A. F. \& Jones, G. B. (1966). Australian fournal of Agricultural Research 17, 69-80.

Krebs, H. A., Hems, R., Weidemann, M. J. \& Speake, R. W. (1966). Biochemical fournal ror, 247-249.

Leng, R. A. (1970). Advances in Veterinary Science 14, 209-260.

Lindsay, D. B. \& Buttery, P. J. (1980). In Protein Deposition in Animals, pp. 125-146 [P. J. Buttery and D. B. Lindsay, editors]. London: Butterworths.

MacRae, J. C., Milne, J. A., Wilson, S. \& Spence, A. M. (1979). British fournal of Nutrition 42, 525-534.

Mann, J. \& Gurpide, E. (I966). Fournal of Clinical Endocrinology and Metabolism 26, $1346-1354$.

Mayes, R. W., Lamb, C. S. \& Colgrove, P. M. (1983). Proceedings of the Nutrition Society 42, I $32 \mathrm{~A}$.

Mayes, R. W., Milne, J. A., Lamb, C. S. \& Spence, A. M. (1981), Proceedings of the Nutrition Society $40,9 \mathrm{~A}$.

Morant, S. V., Ridley, J. L. \& Sutton, J. D. (1978). British Fournal of Nutrition 39, 45 $1-462$.

Murray, R. M., Bryant, A. M. \& Leng, R. A. (1976). British fournal of Nutrition 36, $1-14$.

Nolan, J. V., Norton, B. W. \& Leng, R. A. (1976). British fournal of Nutrition 35, 127-147.

Pethick, D. W. \& Lindsay, D. B. (1982). British Fournal of Nutrition 48, 549-564.

Pethick, D. W., Lindsay, D. B., Barker, P. J. \& Northrop, A. J. (1981). British fournal of Nutrition 46, 97-109.

Radzuik, J., McDonald, T. J., Rubenstein, D. \& Dupre, J. (I978). Metabolism 27, 657-669.

Rowe, J. B., Davies, A. \& Broome, A. W. J. (198I). Proceedings of the Nutrition Society 40, I12A.

Sharp, W. M., Johnson, R. R. \& Owens, F. N. (1982). Fournal of Animal Science 55, 1505-1514.

Shipley, R. A. \& Clark, R. E. (1972). Tracer Methods for In Vivo Kinetics. New York and London: Academic Press.

Smith, H. F., Milne, J. A. \& Mayes, R. W. (I984). Proceedings of the Nutrition Society 43, 40 A.

Sutton, J. D., MacLeod, G. K., Sissons, J. W. \& Johnson, U. W. (1972). Proceedings of the Nutrition Society 31, 67A.

Waterlow, J. C., Garlick, P. J. \& Millward, D. J. (1978). Protein Turnover in Mammalian Tissues and in the Whole Body. Amsterdam: North Holland Publishing Co.

Weber, K. M., Boston, R. C. \& Leaver, D. D. (1980). Australian Fournal of Agricultural Research 31, 773-790.

Whitelaw, F. G. (1974). Proceedings of the Nutrition Society 33, 163-1 71 .

Wilson, S. (1982). Glucose metabolism in hill sheep. PhD Thesis, University of Nottingham.

Wilson, S., MacRae, J. C. \& Buttery, P. J. (1983). British Fournal of Nutrition 50, 303-316. 